\title{
Propranolol and survival from breast cancer: a pooled analysis of European breast cancer cohorts
}

Chris R. Cardwell 1*, Anton Pottegård², Evelien Vaes³, Hans Garmo ${ }^{4,5}$, Liam J. Murray ${ }^{1}$, Chris Brown ${ }^{6}$, Pauline A. J. Vissers ${ }^{7}$, Michael O'Rorke', Kala Visvanathan ${ }^{8}$, Deirdre Cronin-Fenton ${ }^{9}$, Harlinde De Schutter ${ }^{3}$, Mats Lambe ${ }^{5,10}$, Des G. Powe ${ }^{11}$, Myrthe P. P. van Herk-Sukel ${ }^{12}$, Anna Gavin ${ }^{1,13}$, Søren Friis ${ }^{14}$, Linda Sharp ${ }^{15+}$ and Kathleen Bennett ${ }^{16+}$

\begin{abstract}
Background: Preclinical studies have demonstrated that propranolol inhibits several pathways involved in breast cancer progression and metastasis. We investigated whether breast cancer patients who used propranolol, or other non-selective beta-blockers, had reduced breast cancer-specific or all-cause mortality in eight European cohorts.

Methods: Incident breast cancer patients were identified from eight cancer registries and compiled through the European Cancer Pharmacoepidemiology Network. Propranolol and non-selective beta-blocker use was ascertained for each patient. Breast cancer-specific and all-cause mortality were available for five and eight cohorts, respectively. Cox regression models were used to calculate hazard ratios (HR) and $95 \%$ confidence intervals (Cls) for cancerspecific and all-cause mortality by propranolol and non-selective beta-blocker use. HRs were pooled across cohorts using meta-analysis techniques. Dose-response analyses by number of prescriptions were also performed. Analyses were repeated investigating propranolol use before cancer diagnosis.

Results: The combined study population included 55,252 and 133,251 breast cancer patients in the analysis of breast cancer-specific and all-cause mortality respectively. Overall, there was no association between propranolol use after diagnosis of breast cancer and breast cancer-specific or all-cause mortality (fully adjusted HR $=0.94,95 \%$ $\mathrm{Cl}, 0.77,1.16$ and $\mathrm{HR}=1.09,95 \% \mathrm{Cl}, 0.93,1.28$, respectively). There was little evidence of a dose-response relationship. There was also no association between propranolol use before breast cancer diagnosis and breast cancer-specific or all-cause mortality (fully adjusted $\mathrm{HR}=1.03,95 \% \mathrm{Cl}, 0.86,1.22$ and $\mathrm{HR}=1.02,95 \% \mathrm{Cl}, 0.94,1.10$, respectively). Similar null associations were observed for non-selective beta-blockers.
\end{abstract}

Conclusions: In this large pooled analysis of breast cancer patients, use of propranolol or non-selective beta-blockers was not associated with improved survival.

Keywords: Breast cancer, Mortality, Beta-blocker, Cohort

\footnotetext{
* Correspondence: c.cardwell@qub.ac.uk

${ }^{\dagger}$ Equal contributors

${ }^{1}$ Institute of Clinical Sciences Block B, Centre for Public Health, Queen's

University Belfast, Royal Victoria Hospital, Belfast BT12 6BA, UK

Full list of author information is available at the end of the article
} 


\section{Background}

Beta-blockers, used for heart disease and hypertension [1], act by inhibiting beta-adrenergic receptors. Recent studies have shown that breast cancer tissue expresses betaadrenergic receptors [2], particularly type 2 beta-adrenergic receptors [3]. Numerous in-vitro studies have demonstrated that beta-blockers can disrupt migratory activity and inhibit angiogenesis of cancer cells $[4,5]$. In particular, propranolol appears to have potent anti-migratory and anti-angiogenic properties as demonstrated in cancer cell lines and animal models [4-10]. This preclinical evidence has led to calls for randomised controlled trials of propranolol as adjuvant therapy in breast cancer patients [11]; however, although early phase trials are underway $[12,13]$, phase 3 trials have not been conducted to date.

Only three observational studies have previously investigated the association between propranolol use and breast cancer outcomes. In 2011, an Irish study observed an $80 \%$ reduction in breast cancer-specific mortality among patients who used propranolol in the year prior to diagnosis [14]. No association was observed between propranolol use after diagnosis and breast cancer-specific mortality in an English study [15] or between propranolol use after diagnosis and breast cancer recurrence in a Danish study [16]. However, these studies had limited power because of the small numbers of breast cancer patients using propranolol, reflecting the low prevalence of propranolol use which in each study was under 5\% [14-16]. Therefore, a need remains to further investigate propranolol (and other non-selective beta-blockers) and survival in breast cancer patients to inform the decision on whether to conduct large phase 3 randomised controlled trials of propranolol as adjuvant cancer therapy in breast cancer patients.

Consequently, utilising the European Cancer Pharmacoepidemiology Network [17], we conducted a pooled analysis of eight cohorts of breast cancer patients from across Europe to examine whether use of propranolol (or other non-selective beta-blockers) is associated with improved breast cancer-specific and all-cause mortality.

\section{Methods}

\section{Data sources}

Eight cohorts of breast cancer patients from across Europe (including Belgium, Denmark, England, the Netherlands, Northern Ireland, Republic of Ireland, Scotland and Sweden) were compiled through the European Cancer Pharmacoepidemiology Network [17]. Characteristics of these cohorts are presented in Table 1. The association between propranolol use and cancer mortality was examined previously within the English cohort [15] (although using a nested case- control design) and the Republic of Ireland cohort [14] (although this analysis did not investigate propranolol use after diagnosis, had shorter follow-up and had substantially fewer cases). Cancer recurrence was investigated previously in the Danish cohort [16] (although the earlier analysis was based on fewer than $20 \%$ of the breast cancer patients included in the present analysis and did not investigate mortality). Previous studies have reported detailed descriptions of the medication data available and/or linkages available in the cohorts from Denmark [18-20], England [21], the Netherlands [22, 23], Northern Ireland [24], Belgium [25], Republic of Ireland [26], Scotland [27] and Sweden [28, 29].

\section{Inclusion criteria}

All cohorts identified incident invasive breast cancer patients from cancer registries. The year of diagnosis for included breast cancer patients varied across the cohorts from 1998 to 2012. Patients with other invasive cancer diagnoses (apart from non-melanoma skin cancer) prior to their breast cancer diagnosis were excluded.

\section{Exposure}

Propranolol and all non-selective beta-blocker use (including propranolol, sotalol, timolol, nadolol, carvedilol, pindolol, oxprenolol and labetolol) was ascertained from electronic dispensing records in five cohorts, GP prescribing records in two cohorts and health insurance records in one cohort (see Table 1).

\section{Outcome}

In seven of the cohorts, mortality was ascertained from national death records; social security records were used in one cohort (see Table 1). Breast cancer-specific mortality was defined as breast cancer being the underlying cause of death and was available in five cohorts. All-cause mortality was available in all cohorts.

\section{Covariates}

The covariates available varied between cohorts and were obtained from a number of sources including cancer registries, hospital admissions, prescriptions, GPs and health insurance databases (see Table 1). The covariates recorded included: age, year of cancer diagnosis, stage, grade, cancer treatment within the first 6 months after diagnosis (including information on cancerdirected surgery, chemotherapy, radiotherapy), medication use (including tamoxifen, aromatase inhibitors, hormone replacement therapy (prior to diagnosis), aspirin [30], statins [31]) and comorbidities prior to diagnosis. Cancer-directed surgery, chemotherapy and radiotherapy were taken from cancer registry records, apart from in Belgium where insurance claims were used and in 
Table 1 Characteristics of the included cohorts

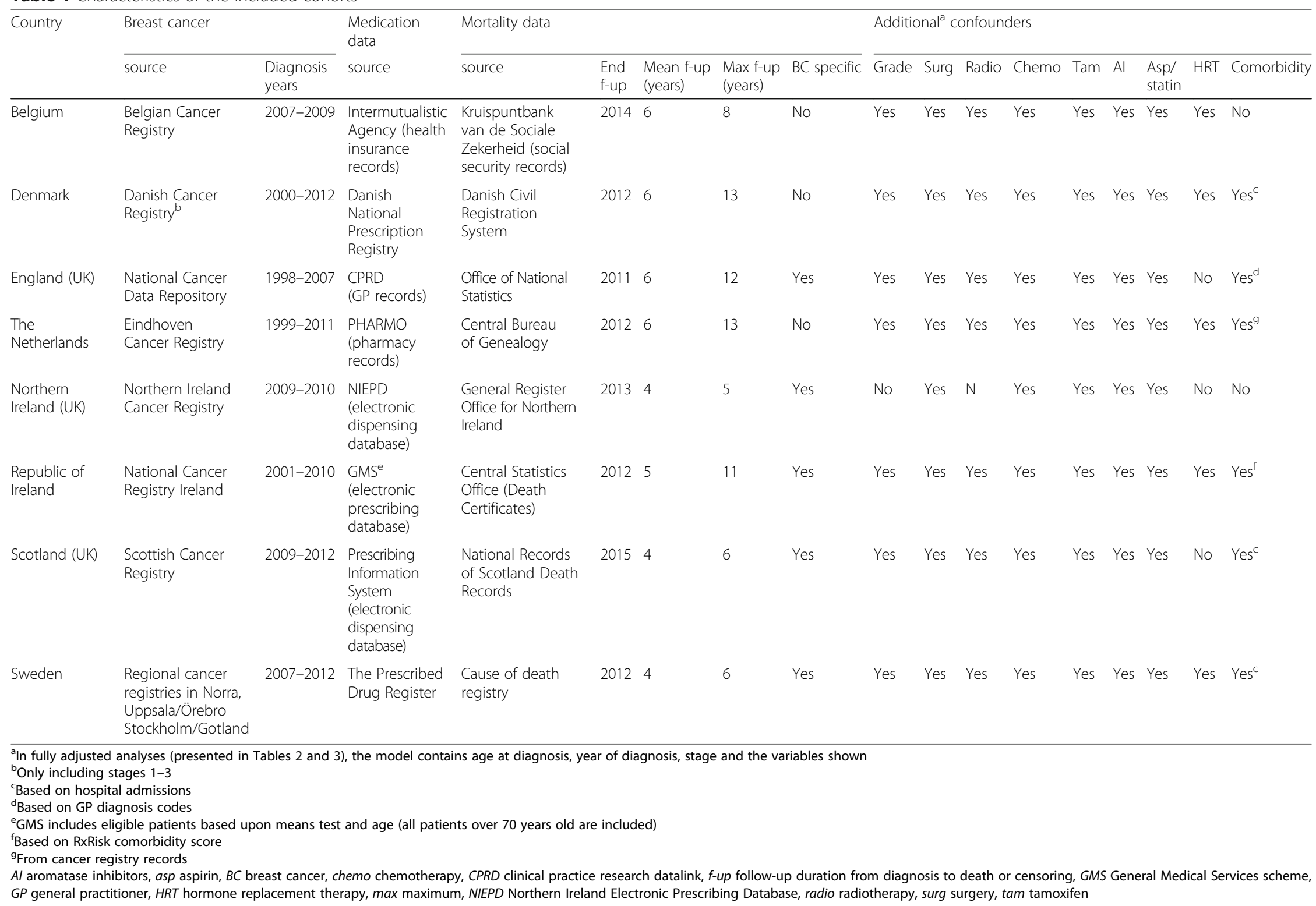


Denmark where Patient Registry records were used. Comorbidities, largely including those in the Charlson comorbidity index [32], were taken from hospital admission records in Denmark, Scotland and Sweden, from GP records in England and from cancer registry records in the Netherlands. In the cohorts from the Netherlands, Denmark and England, adjustments for comorbidity were made for cerebrovascular disease, chronic pulmonary disease, congestive heart disease, diabetes, myocardial infarction, peptic ulcer disease, peripheral vascular disease and renal disease. In Sweden additional adjustments were made for liver disease and in Scotland additional adjustments were made for liver disease and diabetes complications. In the Republic of Ireland cohort, comorbidity information was based upon prescribing information using the RxRisk score [33]. Oestrogen use was based upon HRT use any time prior to diagnosis in the Netherlands, HRT or oral contraceptive use in the year prior to diagnosis in Denmark or HRT use in the year prior to diagnosis in Sweden, the Republic of Ireland, Belgium and Scotland. Tamoxifen and aromatase inhibitor use was obtained from prescription records, except in Denmark were a single more complete endocrine therapy variable, based upon Patient Registry records, was used instead.

\section{Statistical analysis}

We performed a two-stage analysis procedure allowing for adjustment of covariates which were not uniformly defined, coded or available across cohorts [34]. In the main analysis of medication use after diagnosis, the patients in each cohort were followed from 1 year after breast cancer diagnosis to death or end of follow-up, whichever was sooner. Patients who had died in the first year after breast cancer diagnosis (or who had less than 1 year of follow-up) were excluded because it seemed unlikely that propranolol use after diagnosis could reduce mortality within such a short period. In the main analysis, propranolol use was modelled as a time-varying covariate to avoid immortal time bias [35]; that is, patients were initially considered non-users and then became users a lag of 1 year after their first propranolol prescription. The use of a lag period is recommended in studies of medication use and cancer survival [36] because prescriptions filled shortly prior to death may reflect end-of-life treatment. In dose-response analyses, one propranolol prescription corresponded to 1 month of use, except for Denmark where one prescription corresponded to 3 months of use (based on the average duration of propranolol prescriptions in Denmark). In dose-response analyses, an individual was considered a non-user prior to 1 year after first medication usage, a user of $0-1$ year for prescriptions from 1 year after first prescription to 1 year of prescriptions (considered four prescriptions in Denmark and 12 prescriptions in all other countries) and a greater user after this time. Time-dependent Cox regression models were used to calculate hazard ratios (HRs) and $95 \%$ confidence intervals (CIs) for breast cancerspecific death in propranolol users compared with propranolol non-users. An unadjusted analysis was first conducted, then an adjusted analysis (including just the covariates age and year of diagnosis in the model, which were available in all cohorts) and finally a fully adjusted analysis was conducted (including all covariates available within each cohort, as presented in Table 1, in the model). The summary HRs and standard errors (SEs) from the eight cohorts were combined using random effects models to calculate pooled HRs [37] and the consistency of HRs was investigated using chi-squared tests for heterogeneity and $I^{2}$ statistics [38]. The analyses were repeated for all-cause mortality. Analyses were then repeated comparing all non-selective beta-blockers users with nonselective beta-blocker non-users and comparing all beta-blocker users with beta-blocker non-users. A sensitivity analysis was conducted restricting the cohorts to patients with stage 1-3 breast cancer, because it is plausible that the effect might be most evident in those without advanced disease.

We performed two predefined secondary analyses. First, avoiding immortal time bias without requiring complex analyses [39], we compared users of propranolol (and separately users of non-selective betablockers) within the first year after breast cancer diagnosis with non-users within the same period, and started follow-up 1 year after breast cancer diagnosis. Second, to investigate the potential impact of propranolol use earlier in the process of cancer development, we performed a separate analysis of medication use before breast cancer diagnosis comparing time to death in propranolol (and non-selective beta-blockers) users with non-users in the year prior to diagnosis, restricted to individuals with at least 1 year of medication records prior to diagnosis. In analysis of prediagnostic medication use, patients who died in the first year after diagnosis (who had follow-up of less than 1 year) were not excluded.

\section{Results}

\section{Patient cohorts}

The pooled analysis for breast-cancer specific and allcause mortality comprised 55,252 newly diagnosed breast cancer patients (in whom there were 5419 breast cancer-specific deaths and 9295 all-cause deaths) and 133,251 newly diagnosed breast cancer patients (in whom there were 25,472 all-cause deaths), respectively. 
Table 2 Characteristics of breast cancer patients by propranolol and non-selective beta-blocker use in the year after diagnosis

\begin{tabular}{|c|c|c|c|c|c|c|c|c|}
\hline \multirow{3}{*}{ Characteristic } & \multicolumn{4}{|c|}{ Propranolol in year after diagnosis $^{a}$} & \multicolumn{4}{|c|}{ Non-selective beta-blocker in year after diagnosis ${ }^{a}$} \\
\hline & \multicolumn{2}{|c|}{ Users } & \multicolumn{2}{|c|}{ Non-users $^{\mathrm{b}}$} & \multicolumn{2}{|c|}{ Users } & \multicolumn{2}{|c|}{ Non-users ${ }^{c}$} \\
\hline & $n$ & $\%$ & $n$ & $\%$ & $n$ & $\%$ & n & $\%$ \\
\hline \multicolumn{9}{|l|}{ Country } \\
\hline Belgium & 984 & 35.7 & 25,021 & 19.2 & 2131 & 42.1 & 23,874 & 18.6 \\
\hline Denmark & 615 & 22.3 & 44,049 & 33.8 & 1198 & 23.6 & 43,466 & 33.9 \\
\hline England & 212 & 7.7 & 9602 & 7.4 & 299 & 5.9 & 9515 & 7.4 \\
\hline The Netherlands & 78 & 2.8 & 7252 & 5.6 & 203 & 4.0 & 7130 & 5.6 \\
\hline Northern Ireland & 70 & 2.5 & 2106 & 1.6 & 82 & 1.6 & 2094 & 1.6 \\
\hline Republic of Ireland & 142 & 5.2 & 9720 & 7.4 & 250 & 4.9 & 9612 & 7.5 \\
\hline Scotland & 400 & 14.5 & 14,740 & 11.3 & 468 & 9.2 & 14,672 & 11.4 \\
\hline Sweden & 255 & 9.3 & 18,005 & 13.8 & 436 & 8.6 & 17,824 & 13.9 \\
\hline \multicolumn{9}{|l|}{ Year of cancer diagnosis } \\
\hline 1995-1999 & 61 & 2.2 & 2495 & 1.9 & 84 & 1.7 & 2472 & 1.9 \\
\hline $2000-2004$ & 480 & 17.4 & 27,621 & 21.2 & 832 & 16.4 & 27,269 & 21.3 \\
\hline 2005-2009 & 1572 & 57.0 & 66,186 & 50.7 & 3219 & 63.5 & 64,542 & 50.3 \\
\hline 2010-2014 & 643 & 23.3 & 34,193 & 26.2 & 932 & 18.4 & 33,904 & 26.4 \\
\hline \multicolumn{9}{|l|}{ Age at cancer diagnosis } \\
\hline$<40$ & 97 & 3.5 & 5591 & 4.3 & 110 & 2.2 & 5578 & 4.4 \\
\hline $40-49$ & 444 & 16.1 & 19,688 & 15.1 & 540 & 10.7 & 19,592 & 15.3 \\
\hline $50-59$ & 730 & 26.5 & 31,297 & 24.0 & 1031 & 20.3 & 30,996 & 24.2 \\
\hline $60-69$ & 768 & 27.9 & 35,528 & 27.2 & 1419 & 28.0 & 34,877 & 27.2 \\
\hline $70-79$ & 491 & 17.8 & 23,488 & 18.0 & 1235 & 24.4 & 22,744 & 17.7 \\
\hline $80-89$ & 200 & 7.3 & 12,974 & 9.9 & 647 & 12.8 & 12,527 & 9.8 \\
\hline$\geq 90$ & 26 & 0.9 & 1929 & 1.5 & 82 & 1.6 & 1873 & 1.5 \\
\hline \multicolumn{9}{|l|}{ Stage } \\
\hline 1 & 965 & 35.0 & 49,458 & 37.9 & 1735 & 34.2 & 48,669 & 38.0 \\
\hline 2 & 927 & 33.6 & 41,797 & 32.0 & 1718 & 33.9 & 41,006 & 32.0 \\
\hline 3 & 284 & 10.3 & 9073 & 7.0 & 510 & 10.1 & 8847 & 6.9 \\
\hline 4 & 138 & 5.0 & 5086 & 3.9 & 258 & 5.1 & 4966 & 3.9 \\
\hline Missing & 442 & 16.0 & 25,081 & 19.2 & 843 & 16.6 & 24,699 & 19.3 \\
\hline \multicolumn{9}{|l|}{ Grade } \\
\hline Well differentiated & 365 & 17.2 & 16,827 & 19.7 & 662 & 17.2 & 16,530 & 19.7 \\
\hline Moderately differentiated & 885 & 41.6 & 34,600 & 40.5 & 1543 & 40.2 & 33,942 & 40.5 \\
\hline Poorly differentiated & 639 & 30.0 & 22,964 & 26.9 & 1109 & 28.9 & 22,494 & 26.8 \\
\hline Missing & 239 & 11.2 & 11,115 & 13.0 & 529 & 13.8 & 10,825 & 12.9 \\
\hline \multicolumn{9}{|c|}{ Cancer treatment within 6 months of cancer diagnosis } \\
\hline Surgery & 2425 & 88.0 & 114,271 & 87.6 & 4387 & 86.6 & 112,309 & 87.7 \\
\hline Chemotherapy & 1034 & 37.6 & 46,018 & 35.3 & 1608 & 31.8 & 45,444 & 35.5 \\
\hline Radiotherapy $^{d}$ & 1463 & 54.6 & 68,817 & 53.7 & 2649 & 53.2 & 67,631 & 53.7 \\
\hline \multicolumn{9}{|c|}{ Medication use in year after diagnosis } \\
\hline Aromatase inhibitor ${ }^{\mathrm{e}}$ & 724 & 33.8 & 29,176 & 33.8 & 1459 & 37.7 & 28,441 & 33.6 \\
\hline Tamoxifen $^{\mathrm{e}}$ & 1064 & 49.7 & 39,087 & 45.2 & 1765 & 45.6 & 38,386 & 45.3 \\
\hline Statin & 532 & 19.3 & 22,245 & 17.0 & 1353 & 26.7 & 21,424 & 16.7 \\
\hline Low-dose aspirin & 368 & 13.4 & 17,545 & 13.4 & 1097 & 21.6 & 16,816 & 13.1 \\
\hline
\end{tabular}

\footnotetext{
${ }^{a}$ Restricted to breast cancer patients living more than 1 year after diagnosis
}

${ }^{b}$ Propranolol non-users in the year after diagnosis, but could have used other beta-blockers

'Non-selective beta-blocker non-users in the year after diagnosis, but could have used other beta-blockers

${ }^{\mathrm{d}}$ Refers to radiotherapy within 6 months of breast cancer diagnosis, except in Belgium where radiotherapy was considered within 9 months

${ }^{e}$ Excluding Denmark because aromatase inhibitor and tamoxifen were not recorded separately 
The maximum follow-up in each cohort after diagnosis of breast cancer ranged from 5 to 13 years (see Table 1).

\section{Patient characteristics}

Patient characteristics by propranolol (and nonselective beta-blocker) use in the first year after diagnosis are presented in Table 2. Propranolol users were slightly more likely to have an earlier year of breast cancer diagnosis. Age, stage, grade and cancer treatments were generally similar by propranolol use. There was a higher use of hormone antagonists (tamoxifen $39 \%$ versus $30 \%$ and aromatase inhibitors $26 \%$ versus $23 \%$, respectively) in propranolol users versus non-users, but use of other medications was similar.

\section{Association between propranolol use after diagnosis and breast cancer-specific and all-cause mortality}

Overall 4746 breast cancer patients used propranolol at any time after diagnosis (1768 from Belgian, 1057 from Denmark, 419 from England, 151 from the Netherlands, 107 from Northern Ireland, 232 from the republic of Ireland, 629 from Scotland and 383 from Sweden). Table 3 and Fig. 1 present the findings from the main analysis. Overall, there was little difference in breast cancer-specific mortality or all-cause mortality in propranolol users compared with non-users after diagnosis (fully adjusted $\mathrm{HR}=0.94,95 \% \mathrm{CI}, 0.77,1.16$ and $\mathrm{HR}=1.09,95 \% \mathrm{CI}, 0.93,1.28$, respectively). The associations between propranolol and cancer-specific mortality were fairly consistent across cohorts $\left(I^{2}=0 \%\right.$ and heterogeneity $P=0.56$ ), whereas the association varied more for all-cause mortality $\left(I^{2}=65 \%\right.$ and heterogeneity $\left.P=0.006\right)$. On closer inspection (see Fig. 1) this heterogeneity was partly due to the Belgian estimate; once this was removed the pooled estimate was attenuated slightly (fully adjusted $\mathrm{HR}=1.03,95 \% \mathrm{CI}, 0.88,1.20)$ and the heterogeneity was reduced $\left(I^{2}=39 \%\right.$ and heterogeneity $\left.P=0.02\right)$. There was little evidence of a dose-response association; compared with propranolol non-users, there was no association between use of more than 1 year of propranolol prescriptions and cancer-specific or all-cause mortality (fully adjusted HR = 0.93, 95\% CI, 0.46, 1.90 and $\mathrm{HR}=1.09,95 \% \mathrm{CI}, 0.85,1.40$, respectively). Similar null associations were observed for cancer-specific mortality when comparing users of nonselective beta-blockers with non-users of non-selective beta-blockers (see Table 3).

\section{Secondary and sensitivity analyses}

Secondary and sensitivity analyses are presented in Table 4. In sensitivity analyses restricting the cohorts to stage 1-3 breast cancer patients only, the associations between propranolol and cancer-specific and allcause mortality was similar to those for the main analysis (see Table 4). In secondary analysis there was no evidence of an inverse association between any betablocker use after diagnosis and cancer-specific or allcause mortality (fully adjusted $\mathrm{HR}=1.07,95 \% \mathrm{CI}$, $0.99,1.16$ and $\mathrm{HR}=1.12,95 \% \mathrm{CI}, 1.05,1.20$, respectively). The secondary analysis based upon medication use in the first year after diagnosis also produced similar results for propranolol and cancer-specific and all-cause mortality (fully adjusted $\mathrm{HR}=1.07,95 \% \mathrm{CI}$, $0.72,1.60$ and $\mathrm{HR}=1.04,95 \% \mathrm{CI}, 0.89,1.21$, respectively).

Table 4 also presents results for the analysis of propranolol use before diagnosis. Propranolol use in the year before diagnosis was not associated with reduced cancer-specific or all-cause mortality (fully adjusted HR $=1.03,95 \% \mathrm{CI}, 0.86,1.22$ and $\mathrm{HR}=1.02,95 \% \mathrm{CI}, 0.94$, 1.10 , respectively). In all secondary analyses of nonselective beta-blocker use, similar associations were observed to those for propranolol use (see Table 4).

\section{Discussion}

This large pooled analysis of breast cancer patients did not present convincing evidence of reduced cancerspecific or all-cause mortality in breast cancer patients who used propranolol or non-selective beta-blockers either before or after breast cancer diagnosis.

Our pooled analysis supports the findings of two earlier epidemiological studies of the association between propranolol use after diagnosis and cancer outcomes $[15,16]$. The first, an earlier analysis of Danish data [16], showed no association between propranolol use after diagnosis and recurrence (adjusted HR =1.3, 95\% CI, 0.92, 1.9); however, that study did not investigate mortality or the influence of propranolol use before diagnosis. The second study, an earlier analysis of English data [15], based upon a casecontrol design, showed no association between propranolol and cancer-specific mortality (adjusted HR $=0.98,95 \% \mathrm{CI}$, $0.57,1.71)$.

Our pooled analysis also showed no reduction in cancerspecific mortality associated with propranolol use before diagnosis and therefore does not support the results of an earlier Irish study, the only previous study to investigate this association, which observed an $80 \%$ reduction in breast cancer-specific mortality (adjusted HR $=0.19,95 \% \mathrm{CI}, 0.06$ 0.60 ) in 46 breast cancer patients using propranolol in the year prior to diagnosis [14].

The main strength of our analysis is statistical power; this is the largest study yet to investigate the association between use of propranolol and cancer outcomes in breast cancer patients. Despite this, there remains the possibility of type 2 error and we cannot rule out a weak protective effect of propranolol on cancer-specific mortality. Other strengths include the long duration of follow-up, which was up to 13 years following breast cancer diagnosis in some cohorts. The use of routinely 
Table 3 Pooled analysis of the association between propranolol and non-selective beta-blocker use after breast cancer diagnosis and breast cancer-specific and all-cause mortality

\begin{tabular}{|c|c|c|c|c|c|c|c|c|c|c|c|c|}
\hline \multirow[t]{2}{*}{ Medication usage } & \multirow{2}{*}{$\begin{array}{l}\text { Cancer-specific/ } \\
\text { all-cause mortality }\end{array}$} & \multirow{2}{*}{$\begin{array}{c}\text { All } \\
\text { patients }\end{array}$} & \multirow{2}{*}{$\begin{array}{l}\text { Person- } \\
\text { years }\end{array}$} & \multicolumn{3}{|c|}{ Unadjusted } & \multicolumn{3}{|c|}{ Adjusted for age and year } & \multicolumn{3}{|c|}{ Fully adjusted $^{a}$} \\
\hline & & & & $\mathrm{HR}(95 \% \mathrm{Cl})$ & $P$ & Hetero $P^{2}(P)$ & $\mathrm{HR}(95 \% \mathrm{Cl})$ & $P$ & Hetero $P^{2}(P)$ & $\mathrm{HR}(95 \% \mathrm{Cl})$ & $P$ & Hetero $P^{2}(P)$ \\
\hline \multicolumn{13}{|l|}{ Breast cancer-specific mortality } \\
\hline Propranolol non-user & 5291 & 53,482 & 176,723 & 1.00 (ref. cat.) & & & 1.00 (ref. cat.) & & & 1.00 (ref. cat.) & & \\
\hline Propranolol user ${ }^{\mathrm{b}}$ & 128 & 1770 & 4989 & $0.92(0.77,1.10)$ & 0.36 & $0 \%(0.75)$ & $0.97(0.82,1.16)$ & 0.77 & $0 \%(0.84)$ & $0.94(0.77,1.16)$ & 0.56 & $0 \%(0.56)$ \\
\hline \multicolumn{13}{|l|}{ Propranolol prescriptions } \\
\hline $\begin{array}{l}<1 \text { year of } \\
\text { prescriptions }\end{array}$ & 88 & 1217 & 3703 & $1.00(0.79,1.26)$ & 0.98 & $22 \%(0.27)$ & $1.09(0.88,1.35)$ & 0.42 & $9 \%(0.35)$ & $1.01(0.80,1.27)$ & 0.96 & $0 \%(0.62)$ \\
\hline$\geq 1$ year of prescriptions ${ }^{c}$ & 40 & 553 & 1286 & $0.82(0.56,1.21)$ & 0.32 & $3 \%(0.38)$ & $0.80(0.54,1.17)$ & 0.25 & $2 \%(0.38)$ & $0.93(0.46,1.90)$ & 0.84 & $63 \%(0.04)$ \\
\hline Non-selective bb non-user & 5215 & 52,903 & 175,007 & 1.00 (ref. cat.) & & & 1.00 (ref. cat.) & & & 1.00 (ref. cat.) & & \\
\hline Non-selective bb user ${ }^{\mathrm{b}}$ & 204 & 2349 & 6706 & $1.08(0.94,1.24)$ & 0.31 & $0 \%(0.51)$ & $1.07(0.93,1.23)$ & 0.37 & $0 \%(0.92)$ & $1.01(0.85,1.20)$ & 0.90 & $0 \%(0.47)$ \\
\hline \multicolumn{13}{|l|}{ Non-selective bb prescriptions } \\
\hline$<1$ year of prescriptions ${ }^{c}$ & 145 & 1466 & 4555 & $1.13(0.93,1.37)$ & 0.22 & $22 \%(0.27)$ & $1.16(0.99,1.37)$ & 0.07 & $0 \%(0.55)$ & $1.10(0.90,1.34)$ & 0.36 & $0 \%(0.70)$ \\
\hline$\geq 1$ year of prescriptions ${ }^{c}$ & 59 & 883 & 2149 & $1.02(0.78,1.31)$ & 0.91 & $0 \%(0.72)$ & $0.92(0.71,1.19)$ & 0.53 & $0 \%(0.83)$ & $0.97(0.63,1.48)$ & 0.88 & $46 \%(0.14)$ \\
\hline \multicolumn{13}{|l|}{ All-cause mortality } \\
\hline Propranolol non-user & 24,654 & 128,505 & 554,765 & 1.00 (ref. cat.) & & & 1.00 (ref. cat.) & & & 1.00 (ref. cat.) & & \\
\hline Propranolol user ${ }^{\mathrm{b}}$ & 818 & 4746 & 16,202 & $1.04(0.86,1.27)$ & 0.68 & $82 \%(<0.01)$ & $1.13(0.93,1.37)$ & 0.21 & $81 \%(<0.01)$ & $1.09(0.93,1.28)$ & 0.27 & $65 \%(0.006)$ \\
\hline \multicolumn{13}{|l|}{ Propranolol prescriptions } \\
\hline$<1$ year of prescriptions ${ }^{c}$ & 548 & 3099 & 10,977 & $1.01(0.78,1.32)$ & 0.92 & $85 \%(<0.01)$ & $1.20(0.93,1.53)$ & 0.16 & $83 \%(<0.01)$ & $1.15(0.95,1.39)$ & 0.16 & $62 \%(0.01)$ \\
\hline$\geq 1$ year of prescriptions ${ }^{c}$ & 270 & 1647 & 5225 & $1.18(0.97,1.44)$ & 0.10 & $45 \%(0.09)$ & $1.10(0.96,1.26)$ & 0.17 & $10 \%(0.35)$ & $1.09(0.85,1.40)$ & 0.48 & $55 \%(0.04)$ \\
\hline Non-selective bb non-user & 23,740 & 125,320 & 543,344 & 1.00 (ref. cat.) & & & 1.00 (ref. cat.) & & & 1.00 (ref. cat.) & & \\
\hline Non-selective bb user ${ }^{\mathrm{b}}$ & 1732 & 7931 & 27,624 & $1.34(1.14,1.58)$ & 0.001 & $87 \%(<0.01)$ & $1.22(1.09,1.36)$ & 0.001 & $70 \%(<0.01)$ & $1.16(1.02,1.32)$ & 0.02 & $71 \%(<0.01)$ \\
\hline \multicolumn{13}{|l|}{ Non-selective bb prescriptions } \\
\hline$<1$ year of prescriptions ${ }^{c}$ & 1012 & 4512 & 17,074 & $1.23(0.98,1.55)$ & 0.08 & $89 \%(<0.01)$ & $1.22(1.04,1.43)$ & 0.02 & $75 \%(<0.01)$ & $1.19(1.04,1.36)$ & 0.01 & $54 \%(0.03)$ \\
\hline$\geq 1$ year of prescriptions ${ }^{c}$ & 720 & 3419 & 10,549 & $1.67(1.49,1.87)$ & $<0.001$ & $39 \%(0.13)$ & $1.30(1.21,1.40)$ & $<0.001$ & $0 \%(0.61)$ & $1.23(1.04,1.45)$ & 0.02 & $62 \%(0.02)$ \\
\hline
\end{tabular}
aodel contains age, year, stage and confounders presented in Table 1

${ }^{\mathrm{b}}$ Medication use modelled as a time-varying covariate with an individual considered a non-user prior to 1 year after first medication usage and a user after this time, excludes deaths in the year after cancer diagnosis ${ }^{c}$ Medication use modelled as a time-varying covariate with an individual considered a non-user prior to 1 year after first medication usage, a user of 0-1 year of prescriptions from 1 year after first prescription to 1 year of prescriptions (considered four prescriptions in Denmark and 12 prescriptions in all other countries) and a greater user after this time, excludes deaths in the year after cancer diagnosis

$b b$ beta-blocker, $\mathrm{Cl}$ confidence interval, HR hazard ratio, ref. cat. reference category 


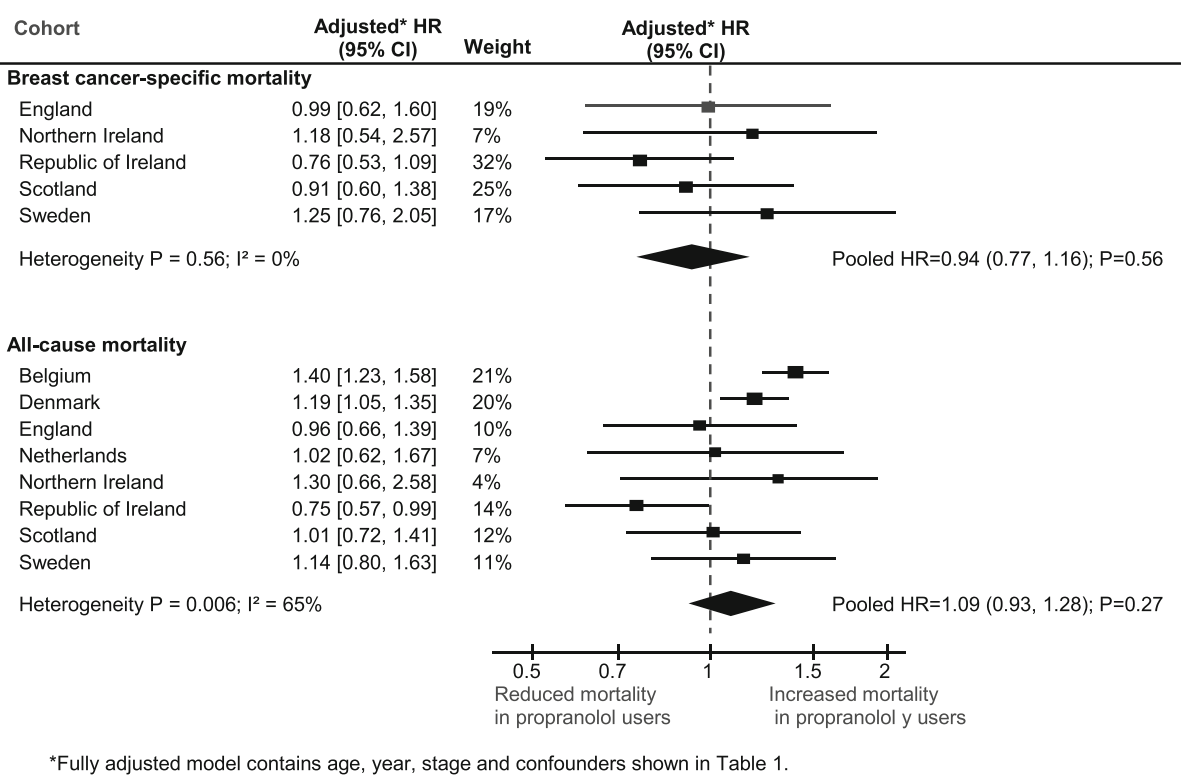

Fig. 1 Association between propranolol and breast cancer-specific and all-cause mortality, by cohort. *Fully adjusted model contains age, year, stage and confounders presented in Table 1. Cl confidence interval, HR hazard ratio

recorded drug information allowed precise evaluations of temporal relationships between propranolol use and mortality and eliminated the potential for recall bias incurred in questionnaire-based studies. Misclassification due to over-the-counter use was likely to be minimal because propranolol can be obtained only by prescription in the included countries.

A weakness of the study is the potential for bias due to the misclassification of breast cancer-specific cause of death on death certificates. However, simulations from a recent methodological study indicate that misclassification of breast cancer-specific cause of death is likely to have relatively small impact on comparisons between groups, assuming misclassification of cancer-specific death is not differential [40]. It should be noted that cohorts from three of the contributing countries [14-16] had been analysed previously with respect to propranolol; however, over $80 \%$ of the breast cancer patients included in the pooled analysis had not been analysed previously, and these earlier analyses covered different time periods [14, 16], were based on different study designs [14, 15], used a different outcome [16] or investigated only exposure before diagnosis [14]. There were some differences in the ascertainment of medication use (five studies used dispensing records, two used GP prescribing records and one used health insurance records) and in the ascertainment of mortality (seven studies used national mortality records and one used social security records). These differences may have contributed to the heterogeneity of the association between propranolol and all-cause mortality. This was partly due to the estimate in the Belgian cohort, and after removal of this study the heterogeneity was markedly reduced, but findings for all-cause mortality were similar. In contrast, there was little evidence of heterogeneity in the association between propranolol and cancer-specific mortality.

Oestrogen receptor status was not available in all of the cohorts; however, reanalysis of the propranolol association in the Swedish and Scottish cohorts additionally adjusting for oestrogen receptor status (after including tamoxifen and aromatase inhibitors in the model) made little difference to the estimates (data not shown), suggesting that oestrogen receptor status had limited potential to confound our results. BMI was also not available. The lack of adjustment for BMI could have attenuated propranolol associations because breast cancer patients with higher BMI have worse survival [41]. Similarly, we cannot rule out the effect of residual confounding on the observed associations from other unrecorded variables (such as trastuzumab use, diet, alcohol intake and physical activity) or for variables which were recorded differently between cohorts (such as use of hormone replacement therapy).

\section{Conclusions}

In this large pooled analysis, propranolol and non-selective beta-blocker use, either before or after diagnosis, was not 
Table 4 Secondary and sensitivity analyses for pooled analysis of the association between propranolol and non-selective beta-blocker use and breast cancer-specific and all-cause mortality

\begin{tabular}{|c|c|c|c|c|c|c|c|c|c|}
\hline \multirow[t]{2}{*}{ Medication usage } & \multirow[t]{2}{*}{ Deaths } & \multirow[t]{2}{*}{ Patients } & \multirow[t]{2}{*}{ Person-years } & \multicolumn{3}{|c|}{ Unadjusted } & \multicolumn{3}{|c|}{ Fully adjusted } \\
\hline & & & & HR $(95 \% \mathrm{Cl})$ & $P$ & Hetero $P^{2}(P)$ & Adjusted HR $(95 \% \mathrm{Cl})$ & $P$ & Hetero $P^{2}(P)$ \\
\hline \multicolumn{10}{|l|}{ Breast cancer-specific mortality } \\
\hline \multicolumn{10}{|l|}{ Medication use after diagnosis } \\
\hline \multicolumn{10}{|c|}{ Main time-varying covariate analysis in stage $1-3$ breast cancer patients } \\
\hline Propranolol in stages $1-3$ & 3389 & 44,376 & 112,450 & $1.02(0.82,1.26)$ & 0.88 & $0 \%(0.84)$ & $1.06(0.85,1.33)$ & 0.62 & $0 \%(0.60)$ \\
\hline \multicolumn{10}{|c|}{ Main time-varying covariate analysis in all breast cancer patients } \\
\hline Any beta-blocker & 5419 & 55,252 & 181,714 & $1.25(1.11,1.40)$ & $<0.001$ & $63 \%(0.03)$ & $1.07(0.99,1.16)$ & 0.10 & $0 \%(0.82)$ \\
\hline \multicolumn{10}{|c|}{ Analysis based upon use in year after diagnosis ${ }^{a}$} \\
\hline Propranolol & 5426 & 55,252 & 181,959 & $0.94(0.72,1.21)$ & 0.61 & $35 \%(0.19)$ & $1.07(0.72,1.60)$ & 0.72 & $65 \%(0.02)$ \\
\hline Non-selective beta-blocker & 5426 & 55,252 & 181,959 & $1.10(0.87,1.39)$ & 0.43 & $51 \%(0.09)$ & $1.15(0.85,1.56)$ & 0.35 & $60 \%(0.04)$ \\
\hline \multicolumn{10}{|c|}{ Medication use before diagnosis ${ }^{b}$} \\
\hline Propranolol & 6883 & 53,870 & 215,978 & $0.97(0.82,1.15)$ & 0.73 & $0 \%(0.51)$ & $1.03(0.86,1.22)$ & 0.78 & $3 \%(0.39)$ \\
\hline Non-selective beta-blocker & 6883 & 53,870 & 215,978 & $1.09(0.95,1.25)$ & 0.22 & $0 \%(0.47)$ & $1.05(0.92,1.21)$ & 0.45 & $0 \%(0.68)$ \\
\hline \multicolumn{10}{|l|}{ All-cause mortality } \\
\hline \multicolumn{10}{|l|}{ Medication use after diagnosis } \\
\hline \multicolumn{10}{|c|}{ Main time-varying covariate analysis in stage $1-3$ breast cancer patients } \\
\hline Propranolol in stages $1-3^{c}$ & 17,219 & 96,097 & 382,1512 & $1.07(0.93,1.24)$ & 0.32 & $29 \%(0.21)$ & $1.13(1.02,1.24)$ & 0.02 & $0 \%(0.46)$ \\
\hline \multicolumn{10}{|c|}{ Main time-varying covariate analysis in all breast cancer patients } \\
\hline Any beta-blocker & 25,472 & 133,251 & 570,968 & $1.57(1.41,1.75)$ & $<0.001$ & $92 \%(<0.001)$ & $1.12(1.05,1.20)$ & $<0.001$ & $65 \%(0.006)$ \\
\hline \multicolumn{10}{|c|}{ Analysis based upon use in year after diagnosis ${ }^{\mathrm{a}}$} \\
\hline Propranolol & 25,487 & 133,251 & 571,213 & $1.02(0.89,1.16)$ & 0.82 & $48 \%(0.06)$ & $1.04(0.89,1.21)$ & 0.62 & $48 \%(0.06)$ \\
\hline Non-selective beta-blocker & 25,487 & 133,251 & 571,213 & $1.35(1.17,1.55)$ & $<0.001$ & $78 \%(<0.001)$ & $1.14(0.99,1.30)$ & 0.06 & $68 \%(0.003)$ \\
\hline \multicolumn{10}{|c|}{ Medication use before diagnosis ${ }^{\mathrm{b}}$} \\
\hline Propranolol & 31,556 & 139,760 & 664,448 & $0.97(0.86,1.09)$ & 0.60 & $44 \%(0.09)$ & $1.02(0.94,1.10)$ & 0.68 & $0 \%(0.54)$ \\
\hline Non-selective beta-blocker & 31,556 & 139,760 & 664,448 & $1.30(1.14,1.49)$ & $<0.001$ & $80 \%(<0.001)$ & $1.13(1.06,1.21)$ & $<0.001$ & $27 \%(0.21)$ \\
\hline
\end{tabular}

${ }^{a}$ Simplified analysis, not requiring time-varying covariate use, comparing medication users with non-users in the first year after diagnosis in individuals living more than 1 year after cancer diagnosis; fully adjusted column adjusted for age, year, stage and all confounders presented in Table 1

${ }^{\mathrm{b}}$ Based on use in the year prior to diagnosis, restricted to individuals with 1 year of records prior to diagnosis; fully adjusted column only adjusted for age at diagnosis and year of diagnosis

'Excludes the Belgian cohort

$\mathrm{Cl}$ confidence interval, $H R$ hazard ratio

associated with improved breast cancer-specific or all-cause mortality.

\section{Abbreviations}

Cl: Confidence interval; GP: General practitioner; HR: Hazard ratio; SE: Standard error

\section{Acknowledgements}

The English cohort is based in part on data from the General Practice Research Database obtained under licence from the UK Medicines and Healthcare Regulatory Agency. However, the interpretation and conclusions contained in study are those of the authors alone. Morten Olesen is acknowledged for help with the data management of the Danish cohort. The Belgian cohort is based upon data from the Belgian Cancer Registry $(B C R)$, the Belgian health insurance companies, provided by the Belgian Intermutualistic Agency (IMA), and the Belgian Crossroads bank for Social Security (BCSS), and the authors would like to acknowledge everyone from the BCR, IMA and BCSS who made this work possible. Thanks to Úna McMenamin, and the staff of the Northern Ireland Cancer Registry who assisted in the collection of the Northern Ireland cohort. The authors would like to thank the research coordinators (Lizzie Nicholson and David Bailey) and NHS National Services Scotland for facilitating access and analysis of the Scottish cohort. The authors thank the National Cancer Registry Ireland and the Irish Health Services Executive Primary Care Reimbursements Services for providing access to the data upon which this study was based.

\section{Funding}

The work on the English dataset was supported by a project funding grant from Cancer Research-UK (C19630/A13265). The work on the UK datasets was supported by a United Kingdom National Institute for Health Research Career Development Fellowship to CRC funded by the Health and Social Care Research and Development Division (Public Health Agency, Northern Ireland). The work on the Ireland dataset was supported by a grant from the Health Research Board in Ireland to CB (HRA_HSR/2012/30).

Availability of data and materials

Data from the study cannot be shared. 


\section{Authors' contributions}

The following authors have made substantial contributions: CRC, AP, DGP LJM, DC-F and LS to conception and design; CRC, AP, MOR, CB, MPPvH-S, AG, HDS, EV, LJM, DC-F, PAJV and ML to collection and assembly of data; and $C R C, A P, C B, K B, S F, H D S, E V, L J M, K V, D C-F, P A J V$ and $H G$ to data analysis and interpretation. All authors were involved in drafting the manuscript and all authors have given final approval of the version to be published.

\section{Competing interests}

MPPvH-S is an employee of the PHARMO Institute for Drug Outcomes Research. PHARMO is an independent research institute that performs financially supported studies for government and related healthcare authorities and several pharmaceutical companies. The authors declare that they have no competing interests.

\section{Consent for publication}

\section{Not applicable.}

\section{Ethics approval and consent to participate}

The cohort from England was covered by Multicentre Research Ethics Committee ethical approval for all purely observational research using the Clinical Practice Research Datalink data. The cohort from Scotland had approval from the NHS National Services Scotland Privacy Advisory committee (reference: PAC 36/14). The analysis of the Northern Ireland cohort was approved by the Office of Research Ethics Northern Ireland (reference: 11/NI/ 0095) and the analysis of the Swedish cohort was approved by the ethics committee at Karolinska Institutet (2013/1272-31/4). Ethical review was not obtained or necessary for the Danish cohort because in Denmark ethical approval is not required for purely registry-based studies [42] or for the Netherlands cohort, although the PHARMO compliance committee approved use of the PHARMO Database Network for this study and confirmed no approval was needed. Specific ethical approval was also not obtained for analysis of the Republic of Ireland cohort because the National Cancer Registry Ireland has permission under the Health (Provision of Information) Act 1997 to collect and hold data on all persons diagnosed with cancer in Ireland and the use of that data for research is covered by the Statutory Instrument which established the Registry Board in 1991. The Belgian cohort analysis was conducted within the legal framework of the Belgian Cancer Registry [43] and therefore specific ethical approval for this study was not necessary.

\section{Scientific (medical) writers}

Not applicable.

\begin{abstract}
Author details
'Institute of Clinical Sciences Block B, Centre for Public Health, Queen's University Belfast, Royal Victoria Hospital, Belfast BT12 6BA, UK. ${ }^{2}$ Department of Public Health, University of South Denmark, Odense, Denmark. ${ }^{3}$ Research Department, Belgian Cancer Registry, Brussels, Belgium. ${ }^{4}$ Division of Cancer Studies, Cancer Epidemiology Unit, King's College London, London, UK. ${ }^{5}$ Regional Cancer Centre Uppsala-Örebro, Uppsala, Sweden. ${ }^{6}$ National Cancer Registry Ireland, Cork, Ireland. ${ }^{7}$ Netherlands Comprehensive Cancer Organisation, Utrecht, The Netherlands. ${ }^{8}$ Johns Hopkins University Bloomberg School of Public Health and School of Medicine, Baltimore, USA. ${ }^{9}$ Department of Clinical Epidemiology, Aarhus University, Aarhus, Denmark. ${ }^{10}$ Department of Medical Epidemiology and Biostatistics, Karolinska Institutet, Stockholm, Sweden. ${ }^{11}$ Department of Cellular Pathology, Queens Medical Centre, NUH, Nottingham, UK. ${ }^{2}$ PHARMO Institute for Drug Outcomes Research, Utrecht, The Netherlands. ${ }^{13}$ Northern Ireland Cancer Registry, Queen's University Belfast, Belfast, UK. ${ }^{14}$ Danish Cancer Society Research Center, Danish Cancer Society, Copenhagen, Denmark. ${ }^{15}$ Institute of Health and Society, Newcastle University, Newcastle upon Tyne, UK. ${ }^{16}$ Department of Pharmacology \& Therapeutics, Trinity College Dublin, Dublin, Ireland.
\end{abstract}

Received: 25 April 2016 Accepted: 17 November 2016 Published online: 01 December 2016

\section{References}

1. Aronow WS. Current role of beta-blockers in the treatment of hypertension. Expert Opin Pharmacopther. 2001;11:2599-607.

2. Barron TI, Sharp L, Visvanathan K. Beta-adrenergic blocking drugs in breast cancer: a perspective review. Ther Adv Med Oncol. 2012;4:113-25.
3. Powe DG, Voss MJ, Habashy HO, et al. Alpha- and beta-adrenergic receptor (AR) protein expression is associated with poor clinical outcome in breast cancer: an immunohistochemical study. Breast Cancer Res Treat. 2011;130:457-63.

4. Lang $\mathrm{K}$, Drell $\mathrm{TL}$, Lindecke $\mathrm{A}$, et al. Induction of a metastatogenic tumor cell type by neurotransmitters and its pharmacological inhibition by established drugs. Int J Cancer. 2004;112:231-8.

5. Pasquier E, Ciccolini J, Carre M, et al. Propranolol potentiates the antiangiogenic effects and anti-tumor efficacy of chemotherapy agents: implication in breast cancer treatment. Oncotarget. 2011;2:797-809.

6. Annabi B, Lachambre MP, Plouffe K, Moumdjian R, Beliveau R. Propranolol adrenergic blockade inhibits human brain endothelial cells tubulogenesis and matrix metalloproteinase-9 secretion. Pharmacol Res. 2009;60:438-45.

7. Benish M, Bartal I, Goldfarb Y, et al. Perioperative use of beta-blockers and COX-2 inhibitors may improve immune competence and reduce the risk of tumor metastasis. Ann Surg Oncol. 2008;15:2042-52.

8. Sloan EK, Priceman SJ, Cox BF, et al. The sympathetic nervous system induces a metastatic switch in primary breast cancer. Cancer Res. 2010;70:7042-52.

9. Palm D, Lang K, Niggemann B, et al. The norepinephrine-driven metastasis development of PC-3 human prostate cancer cells in BALB/C nude mice is inhibited by beta-blockers. Int J Cancer. 2006;118:2744-9.

10. Wilson JM, Lorimer E, Tyburski MD, Williams CL. Beta-Adrenergic receptors suppress Rap1B prenylation and promote the metastatic phenotype in breast cancer cells. Cancer Biol Ther. 2015;16:1364-74.

11. Cole SW, Sood AK. Molecular pathways: beta-adrenergic signaling in cancer Clin Cancer Res. 2012;18:1201-6.

12. United States National Institutes of Health. Perioperative administration of COX 2 inhibitors and beta blockers to women undergoing breast cancer surgery. https://www.clinicaltrials.gov/ct2/show/NCT00502684. Accessed 15 Mar 2016.

13. United States National Institutes of Health. Study of propranolol in newly diagnosed breast cancer patients undergoing neoadjuvant chemotherapy. https://clinicaltrials.gov/ct2/show/NCT01847001. Accessed 15 Mar 2016.

14. Barron TI, Connolly RM, Sharp L, Bennett K, Visvanathan K. Beta blockers and breast cancer mortality: a population-based study. J Clin Oncol. 2011;29:2635-44.

15. Cardwell CR, Coleman HG, Murray LJ, Entschladen F, Powe DG. Beta-blocker usage and breast cancer survival: a nested case-control study within a UK clinical practice research datalink cohort. Int J Epidemiol. 2013;42:1852-61.

16. Sorensen GV, Ganz PA, Cole SW, et al. Use of $\beta$-blockers, angiotensinconverting enzyme inhibitors, angiotensin II receptor blockers, and risk of breast cancer recurrence: a Danish nationwide prospective cohort study. J Clin Oncol. 2013;31:2265-72.

17. European Cancer Pharmacoepidemiology Network. http://www. cancerpharmacoepi.eu. Accessed 15 Mar 2016.

18. Kildemoes HW, Sorensen HT, Hallas J. The Danish National Prescription Registry. Scand J Public Health. 2011;39(7 Suppl):38-41.

19. Peeters PJ, Bazelier MT, Vestergaard $P$, et al. Use of metformin and survival of diabetic women with breast cancer. Curr Drug Saf. 2013:8:357-63.

20. Gjerstorff ML. The Danish Cancer Registry. Scand J Public Health. 2011;39(7 Suppl):42-5

21. Herrett E, Gallagher AM, Bhaskaran K, et al. Data resource profile: Clinical Practice Research Datalink (CPRD). Int J Epidemiol. 2015;44(3):827-36.

22. Herings R. PHARMO: a record linkage system for postmarketing surveillance of prescription drugs in the Netherlands. Utrecht: Utrecht University; 1993.

23. van Herk-Sukel MP, van de Poll-Franse LV, Lemmens VE, et al. New opportunities for drug outcomes research in cancer patients: the linkage of the Eindhoven Cancer Registry and the PHARMO Record Linkage System. Eur J Cancer. 2010;46(2):395-404.

24. Maguire A, Hughes C, Cardwell C, O'Reilly D. Psychotropic medications and the transition into care: a national data linkage study. J Am Geriatr Soc. 2013;61(2):215-21.

25. Vlayen J, De Gendt C, Stordeur S, et al. Quality indicators for the management of upper gastrointestinal cancer. Good clinical practice. KCE Reports 200. D/2013/10.273/15. Brussels: Belgian Health Care Knowledge Centre (KCE); 2013.

26. Williams D, Feely J. Pharmacoepidemiology_an Irish perspective. Pharmacoepidemiol Drug Saf. 2001;10(7):641-5.

27. Alvarez-Madrazo S, McTaggart S, Nangle C, Nicholson E, Bennie M. Data resource profile: the Scottish National Prescribing Information System (PIS). Int J Epidemiol. 2016;45(3):714-5f

28. Socialstyrelsen. National Board of Health and Welfare: The Prescribed Drug Register [in Swedish]. http://www.nepi.net/Socialstyrelsenslaekemedelsregister.htm. Accessed 15 Mar 2016. 
29. Wettermark B, Hammar N, Fored CM, et al. The new Swedish Prescribed Drug Register-opportunities for pharmacoepidemiological research and experience from the first six months. Pharmacoepidemiol Drug Saf. 2007;16(7):726-35.

30. Holmes MD, Chen WY, Li L, Hertzmark E, Spiegelman D, Hankinson SE. Aspirin intake and survival after breast cancer. J Clin Oncol. 2010;28:1467-72.

31. Ahern TP, Pedersen L, Tarp M, et al. Statin prescriptions and breast cancer recurrence risk: a Danish nationwide prospective cohort study. J Natl Cancer Inst. 2011;103:1461-8.

32. Khan NF, Perera R, Harper S, Rose PW. Adaptation and validation of the Charlson Index for Read/OXMIS coded databases. BMC Fam Pract. 2010;11:1.

33. Fishman PA, Goodman MU, Hornbrook MC, et al. Risk adjustment using automated ambulatory pharmacy data: the RxRisk model. Med Care. 2003;41:84-99.

34. Stukel TA, Demidenko E, Dykes J, Karagas MR. Two-stage methods for the analysis of pooled data. Stat Med. 2001;20:2115-30.

35. Levesque LE, Hanley JA, Kezouh A, Suissa S. Problem of immortal time bias in cohort studies: example using statins for preventing progression of diabetes. BMJ. 2010;340:b5087.

36. Chubak J, Boudreau DM, Wirtz HS, McKnight B, Weiss NS. Threats to validity of nonrandomized studies of postdiagnosis exposures on cancer recurrence and survival. J Natl Cancer Inst. 2013;105:1456-62.

37. Dersimonian R, Laird N. Meta-analysis in clinical-trials. Control Clin Trials. 1986;:177-88

38. Higgins JP, Thompson SG, Deeks JJ, Altman DG. Measuring inconsistency in meta-analyses. BMJ. 2003;327:557-60.

39. Zhou Z, Rahme E, Abrahamowicz M, Pilote L. Survival bias associated with time-to-treatment initiation in drug effectiveness evaluation: a comparison of methods. Am J Epidemiol. 2005;162:1016-23.

40. Sarfati D, Blakely T, Pearce N. Measuring cancer survival in populations: relative survival vs cancer-specific survival. Int J Epidemiol. 2010;39:598-610.

41. Chan DS, Vieira AR, Aune D, et al. Body mass index and survival in women with breast cancer-systematic literature review and meta-analysis of 82 follow-up studies. Ann Oncol. 2014;25(10):1901-14.

42. Thygesen LC, Daasnes C, Thaulow I, Bronnum-Hansen H. Introduction to Danish (nationwide) registers on health and social issues: structure, access, legislation, and archiving. Scand J Public Health. 2001;39(7 Suppl):12-6.

43. Belgian law Gazette of 22-12-2006: http://www.kankerregister.org/media/ docs/Wetgeving/Staatsbladgezondheidswet13122006pub22122006.pdf. Accessed 15 Mar 2016

\section{Submit your next manuscript to BioMed Central and we will help you at every step:}

- We accept pre-submission inquiries

- Our selector tool helps you to find the most relevant journal

- We provide round the clock customer support

- Convenient online submission

- Thorough peer review

- Inclusion in PubMed and all major indexing services

- Maximum visibility for your research

Submit your manuscript at www.biomedcentral.com/submit

) Biomed Central 